
\title{
25 Research Square \\ Predictive factors for disease recurrence in patients with locally advanced renal cell carcinoma treated with curative surgery
}

\section{Te-Wei Chang}

Taipei City Hospital Zhongxiao Branch https://orcid.org/0000-0001-5827-8548

Wei-Ming Cheng ( $\nabla$ guwmcheng@gmail.com )

Yu-Hua Fan

Taipei Veterans General Hospital

Chih-Chieh Lin

Taipei Veterans General Hospital

\section{Tzu-Ping Lin}

Taipei Veterans General Hospital

\section{Eric Yi-Hsiu Huang}

Taipei Veterans General Hospital

\section{Hsiao-Jen Chung}

Taipei Veterans General Hospital

William J.S. Huang

Taipei Veterans General Hospital

\section{Yen-Hwa Chang}

Taipei Veterans General Hospital

Alex T.L. Lin

Taipei Veterans General Hospital

\section{Research article}

Keywords: renal cell carcinoma, capsule penetration, disease-free survival, Fuhrman grade, prognosis

Posted Date: April 14th, 2020

DOI: https://doi.org/10.21203/rs.3.rs-22622/v1

License: (c) (i) This work is licensed under a Creative Commons Attribution 4.0 International License.

Read Full License 
Version of Record: A version of this preprint was published at Journal of the Chinese Medical Association on March 31st, 2021. See the published version at https://doi.org/10.1097/JCMA.0000000000000501. 


\section{Abstract}

Background Few prognostic factors have been proposed for patients with locally advanced renal cell carcinoma (RCC). This study aimed to investigate the possible predictive factors for disease-free survival (DFS) after curative surgery for RCC stage T3 or higher.

Methods Patients with locally advanced RCC who underwent cure-intended partial or radical nephrectomy, with or without tumor thrombectomy, at our institution from April 1 st , 2005 to October 31 st , 2013 were retrospectively reviewed. Those undergoing cytoreductive nephrectomy were excluded. Preoperative data, including surgical and pathologic characteristics, were assessed for correlation with DFS. Chi-squared tests, multivariate Cox regression analysis, and Kaplan-Meier survival curve analyses were performed to determine potential predictive factors. A P-value less than 0.05 was considered statistically significant.

Results A total of 159 patients were included for analysis. One hundred and nineteen (74.8\%) patients remained disease-free during follow-up. Disease recurrence was found in $40(25.2 \%)$ patients, and pathological T stage, capsule penetration, Fuhrman grade, thrombocytosis, and elevated serum alkaline phosphatase and $y$-glutamyl transpeptidase levels were significantly associated with disease recurrence on univariate analysis. On multivariate analysis, capsule penetration (hazard ratio $[\mathrm{HR}]=2.25, p=0.038$, $95 \%$ confidence interval $[\mathrm{Cl}]=1.05-4.85)$ and Fuhrman grade 3 or $4(\mathrm{HR}=8.06, p=0.003,95 \% \mathrm{Cl}=2.59-$ 25.02) showed significant associations with DFS.

Conclusions In patients with locally advanced RCC, capsule penetration and Fuhrman grade were associated with worse DFS after curative surgery. Urologists should closely monitor patients with capsule penetration and high Fuhrman grades, and adjuvant systemic treatments, other than targeted agents, should be considered.

\section{Background}

Renal cell carcinoma (RCC) is the sixth most common cancer in men, and the ninth most common cancer in women, worldwide [1]. The incidence is approximately 12 per 100,000 persons per year [1, 2]. Since most patients with RCC are asymptomatic, about one-third of patients are diagnosed at a late stage [1].

Radical nephrectomy, with or without thrombectomy, and partial nephrectomy for highly selected cases, are the only curative treatments for patients with locally advanced RCC without distal metastases [3]. There are several prognostic models to predict the treatment response of targeted therapy in metastatic RCC. However, few prognostic factors have been proposed for patients with locally advanced RCC [4, 5].

In this study, we investigated the possible predictive factors for disease-free survival after surgery (DFS) for RCC stage T3 or higher. To the best of our knowledge, this is the first study evaluating the predictive factors of disease recurrence in patients with locally advanced RCC. 


\section{Methods}

We conducted the present research according to the Declaration of Helsinki and the principles of research ethics of our institutional review board. Patients with locally advanced RCC who underwent cure-intended partial or radical nephrectomy, with or without tumor thrombectomy, at our institution from April $1^{\text {st }}, 2005$ to October $31^{\text {st }}, 2013$ were retrospectively recruited from our medical database. Patients with known metastases and those who underwent cytoreductive nephrectomy were excluded. Preoperative data, including patient demographics, biochemical data, and surgical and pathologic characteristics according to the $7^{\text {th }}$ American Joint Committee on Cancer (AJCC), were collected. Patients underwent follow-up chest radiography, abdominal computed tomography, and whole-body bone scans every 3 months for the first 2 years after surgical intervention, or as indicated in cases of newly-developed symptoms. The follow-up interval was extended if no recurrence developed after 2 years. Those without local recurrence or distant metastases were classified as disease-free during follow-up.

Univariate analyses of categorical variables were performed using the Chi-squared test. Multivariate Cox regression and Kaplan-Meier survival curve analyses were also performed to determine the predictive factors of DFS. Statistical analyses were performed using Statistical Analysis Software, Version 9.4 (SAS Institute Inc., Cary, North Carolina, USA). A P-value less than 0.05 was considered as statistically significant.

\section{Results}

A total of 159 patients were included for analysis (110 [69.2\%] males and 49 [30.8\%] females). The mean age at surgery was $62.2 \pm 15.3$ years. Table 1 shows the characteristics of the patient cohort. The mean duration of follow-up was $37.9 \pm 27.9$ months. One hundred and nineteen patients $(74.8 \%)$ remained disease-free during the postoperative follow-up. The mean DFS was $33.0 \pm 26.8$ months. Forty patients (25.2\%) developed disease recurrence.

Table 2 shows the possible predictive factors for disease recurrence according to the univariate analyses. In brief, a pathological stage higher than pT3a, Fuhrman grade of 3 or 4, presence of capsule penetration, thrombocytosis, and elevated alkaline phosphatase (alk-p) and y-glutamyl transpeptidase (rGT) levels were significantly associated with disease recurrence. Age, sex, blood type, surgical method, perioperative blood transfusion, RCC cell type, positive surgical margin (PSM), presence of sarcomatoid differentiation, and adjuvant targeted therapy failed to reach statistical significance.

On multivariate Cox regression analysis, capsule penetration (hazard ratio $[\mathrm{HR}]=2.25,95 \%$ confidence interval $[\mathrm{Cl}]=1.05-4.85, \mathrm{p}=0.038)$ and Fuhrman grade 3 or $4(\mathrm{HR}=8.06, \mathrm{p}=0.003,95 \% \mathrm{Cl}=2.59-$ 25.02) showed significant associations with DFS (Table 3). Other factors, including a pathological stage higher than pT3a, thrombocytosis, and elevated serum alk-p and rGT levels, failed to reach statistical significance in the multivariate analysis. The Kaplan-Meier survival curves for capsule penetration and Fuhrman grade are illustrated in Figure 1 and Figure 2, respectively. 


\section{Discussion}

There are several prognostic systems and nomograms to predict survival after nephrectomy for RCC [68]. However, these systems include RCCs of all stages, rather than focusing on locally advanced RCC, which is technically challenging for urologists, with a potentially different prognosis compared to that for early-stage disease. In the present study, we found that locally advanced RCC with capsule penetration was significantly associated with recurrence after curative surgery, whilst a positive surgical margin, a pathological T stage higher than T3a, administration of adjuvant targeted therapy, and elevated preoperative liver function test results were not significantly related to disease recurrence.

In the present study, capsule penetration was an independent factor for the prediction of DFS in patients with locally advanced RCC treated with curative surgery. This finding is consistent with the literature. A review article of six cohort studies reported that patients with capsule-invaded localized RCC had a 1.80times higher risk of tumor recurrence than did those without capsule invasion [9-14]; however, the included studies did not focus solely on locally advanced RCC. Roos et al. showed that capsular invasion was associated with shorter progression-free survival $(p<0.001)$ and reduced cancer-specific survival $(p$ $=0.011)$ in patients with pT3b/c RCC [15]. The location of capsule penetration has also been shown to influence the prognosis. Minervini et al. found that capsule invasion to the parenchymal side, rather than to perirenal fat tissue, was an independent predictor of progression-free survival [16]. As capsular penetration is such an important predictive factor in RCC, a scoring system to classify the integrity of the capsule, called i-CAP, has been proposed by Snarskis et al. [17]. In brief, our research, along with previous studies, has demonstrated that capsular penetration is a prognostic factor, not only in early-stage RCC, but also in locally advanced RCC.

Higher Fuhrman grade was also an independent predictive factor for DFS in our series. The Fuhrman grade is a well-known predictor for disease progression, not only in early-stage RCC, but also in locally advanced RCC $[18,19]$. For example, in a study utilizing data from a Chinese database, a modified Fuhrman grade of 3 or 4 was one of the independent predictive factors for postoperative cancer-specific survival (CSS) ( $p=0.001, \mathrm{HR}=5.194)$ in patients with locally advanced RCC [20]. Additionally, Schiavina et al. reported that a higher Fuhrman grade was an independent predictor for CSS in T3a RCC [21]. Thus, the present study, along with previous studies, suggests that higher Fuhrman grade is associated with a poor prognosis in patients with locally advanced RCC.

Interestingly, elevated preoperative liver function markers, including alk-p and rGT, were associated with disease recurrence in the univariate, but not multivariate, analyses in the present study. In a systematic review from 2014, the alk-p level was reported as a promising biomarker for the detection of bony metastases in patients with malignancy [22]. However, the usefulness of alk-p in RCC remains controversial.

Kattan et al. developed a nomogram incorporating elevated alk-p to predict 12-month progression-free survival in patients with advanced RCC treated with pazopanib [23]. A similar prognostic model to stratify advanced RCC into different risk groups according to elevated alk-p and other clinical parameters was 
also proposed by Amato et al. [24]. Furthermore, in a large retrospective study of 2,945 patients with RCC who underwent radical nephrectomy for a cure, Margulis et al. reported that elevated alk-p had a negative influence on CSS in patients with local recurrence [25]. On the other hand, Jung et al. found that it was difficult to diagnose bone metastasis using turnover markers, including alk-p, in 72 patients with localized and metastatic RCC [26]. Elevated serum alk-p might be an indicator of micrometastasis in the bone that cannot be detected using current image modalities. Another possible explanation for the conflicting results is the presence of non-metastatic hepatic dysfunction, also known as Stauffer syndrome. It is estimated that this syndrome develops in $13.2 \%$ of patients with RCC [27]. Stauffer syndrome is believed to be associated with higher levels of inflammatory interleukin-6, and imply a poor prognosis $[27,28]$. In another similar retrospective study, paraneoplastic syndrome was one of the independent predictive factors for CSS [20]. The manifestations of this paraneoplastic syndrome, including elevated serum alk-p and rGT, and thrombocytosis, were also correlated with disease recurrence in the univariate analyses of the present study. Further prospective studies that include more patients are warranted to determine the prognostic significance of these clinical parameters in patients with locally advanced RCC before surgical intervention.

PSM is often considered a poor prognostic factor for malignancy [29-31]; however, this remains debatable for RCC. Several studies have shown that PSM has little impact on RCC survival or recurrence [32-34]. PSM does not necessarily indicate residual tumor tissue inside the patient's body. The residual tumor tissue may be too close to the margin to be destroyed during resection with electrocauterization. Moreover, surgery may disturb the blood supply to the residual tumor cells inside the patient's body, and they may not survive after surgical intervention. Further studies are needed to clarify the association between PSM and disease recurrence in patients with locally advanced RCC.

Pathological T stage is a well-known prognostic factor [7, 35, 36]; however, it was not a prognostic factor in our locally advanced RCC series. For most malignancies, a higher T stage suggests a larger tumor size. However, locally advanced RCC is unique compared to other cancers, as a T stage higher than T3 is defined according to its location inside the kidney, as well as its relationships with adjacent structures, especially the great vessels. To perform curative surgery for an RCC higher than T3a is typically demanding, as it usually involves the inferior vena cava, requiring cooperation between urologists and vascular surgeons. It is possible that a selection bias was responsible for the insignificance of T stage found in the present study.

Adjuvant targeted therapy did not improve the prognosis in the present study. This finding is compatible with some reports in the literature. In the PROTECT study, adjuvant pazopanib failed to improve DFS in patients with resected high-grade pT2 or $\geq$ pT3 clear-cell RCC compared to that with placebo [37]. In contrast, adjuvant sunitinib prolonged DFS significantly in patients with locally advanced RCC in the STRAC study [38]. Because of this conflicting data, adjuvant targeted therapy for locally advanced RCC is not recommended in the European Association of Urology and National Comprehensive Cancer Network guidelines. The impact of adjuvant immunotherapy on patients with resected locally advanced RCC remains under investigation. 
The present study was several limitations. First, this was a retrospective study of data from a single center, involving several urologists. The impact of an individual urologist's surgical skills on disease recurrence is hard to clarify. Nevertheless, there was no statistical significance in DFS rates between the different urologists at our institution. Second, there a high proportion of patients with T3a RCC in our patient cohort. This may have been due to the detailed examination of the specimens performed by the pathologists at our institution. Some T1 and T2 RCCs were upstaged to T3a when tumor involvement of segmental blood vessels or perinephric fat was detected. Nevertheless, the present study findings are still valuable because very few studies have focused on the Asian population. Moreover, to the best of our knowledge, this is the first study investigating the prognosis of patients with locally advanced RCC treated with curative nephrectomy. Because of the high risk of disease recurrence and progression, the exploration of prognostic factors can aid in risk stratification, patient counseling, postoperative follow-up, and the decision to administer adjuvant immunotherapy.

\section{Conclusions}

In conclusion, in patients with locally advanced RCC, the presence of capsule penetration and a high Fuhrman grade can predict shorter DFS after curative surgery. Urologists should monitor such patients closely, and adjuvant systemic treatments, other than targeted agents, should be considered. The impact of adjuvant immunotherapy on the prognosis of patients with locally advanced RCC remains unknown. Several ongoing clinical trials will answer this question in the future. Moreover, the development of a nomogram to stratify the risk of disease recurrence may be helpful in clinical practice.

\section{Abbreviations}

AJCC = American Joint Committee on Cancer

alk-p = alkaline phosphatase

CSS = cancer-specific survival

DFS = disease-free survival

$\mathrm{PSM}=$ positive surgical margin

$\mathrm{RCC}=$ renal cell carcinoma

rGT $=$ y-glutamyl transpeptidase

\section{Declarations}

Ethics approval and consent to participate: 
We have consulted the Institutional Review Board of Taipei Veterans General Hospital at the time when we initiated this study. They suggested the review process by the committee was not mandatory since this was a retrospective, pure chart review study. Nevertheless, we conducted the whole study based on the Declaration of Helsinki and the principles of research ethics of our institutional review board.

Consent for publication: Not applicable

Availability of data and materials: Not applicable

Competing interests: The authors declare that they have no competing interests.

Funding: None

Authors' contributions: TWC and WMC were responsible for the manuscript writing. YHF, CCL, TPL, EYHH, HJC, WJSH, YHC, and ATLL contributed to study design and data collection. All authors read and approved the final manuscript.

Acknowledgements: We thank the Center for Public Health, Department of Education and Research, Taipei City Hospital, Taiwan for their valuable contributions in data management and statistical analysis.

\section{References}

1.Siegel RL, Miller KD, Jemal A: Cancer statistics, 2018. CA: a cancer journal for clinicians 2018, 68(1):730 .

2.Rini BI, Campbell SC, Escudier B: Renal cell carcinoma. Lancet (London, England) 2009, 373(9669):1119-1132.

3.Shinder BM, Rhee K, Farrell D, Farber NJ, Stein MN, Jang TL, Singer EA: Surgical Management of Advanced and Metastatic Renal Cell Carcinoma: A Multidisciplinary Approach. Frontiers in oncology 2017, 7:107.

4.Motzer RJ, Mazumdar M, Bacik J, Berg W, Amsterdam A, Ferrara J: Survival and prognostic stratification of 670 patients with advanced renal cell carcinoma. Journal of clinical oncology: official journal of the American Society of Clinical Oncology 1999, 17(8):2530-2540.

5.Shinohara N, Abe T: Prognostic factors and risk classifications for patients with metastatic renal cell carcinoma. International journal of urology: official journal of the Japanese Urological Association 2015, 22(10):888-897.

6.Sorbellini M, Kattan MW, Snyder ME, Reuter V, Motzer R, Goetzl M, McKiernan J, Russo P: $A$ postoperative prognostic nomogram predicting recurrence for patients with conventional clear cell renal cell carcinoma. The Journal of urology 2005, 173(1):48-51. 
7.Karakiewicz PI, Briganti A, Chun FK, Trinh QD, Perrotte P, Ficarra V, Cindolo L, De la Taille A, Tostain J, Mulders PF et al: Multi-institutional validation of a new renal cancer-specific survival nomogram. Journal of clinical oncology: official journal of the American Society of Clinical Oncology 2007, 25(11):13161322.

8.Karakiewicz PI, Suardi N, Capitanio U, Jeldres C, Ficarra V, Cindolo L, de la Taille A, Tostain J, Mulders $\mathrm{PF}$, Bensalah K et al: A preoperative prognostic model for patients treated with nephrectomy for renal cell carcinoma. European urology 2009, 55(2):287-295.

9.Song T, Yin Y, Liao B, Zheng S, Wei Q: Capsular invasion in renal cell carcinoma: a meta-analysis. Urologic oncology 2013, 31(7):1321-1326.

10.Jeong IG, Jeong CW, Hong SK, Kwak C, Lee E, Lee SE: Prognostic implication of capsular invasion without perinephric fat infiltration in localized renal cell carcinoma. Urology 2006, 67(4):709-712.

11.Klatte T, Chung J, Leppert JT, Lam JS, Pantuck AJ, Figlin RA, Belldegrun AS: Prognostic relevance of capsular involvement and collecting system invasion in stage I and II renal cell carcinoma. BJU international 2007, 99(4):821-824.

12.Cho HJ, Kim SJ, Ha US, Hong SH, Kim JC, Choi YJ, Hwang TK: Prognostic value of capsular invasion for localized clear-cell renal cell carcinoma. European urology 2009, 56(6):1006-1012.

13.Rouach Y, Delongchamps N, Timsit MO, Verkarre V, Fontaine E, Peyromaure M, Mejean A: Capsular involvement in patients undergoing partial nephrectomy for localized renal cell carcinoma: an adverse pathological finding? BJU international 2010, 105(5):616-619.

14.Süer E, Ergün G, Baltacı S, Bedük Y: Does Renal Capsular Invasion Have Any Prognostic Value in Localized Renal Cell Carcinoma? The Journal of urology 2008, 180(1):68-71.

15.Roos FC, Weirich J, Victor A, Elsasser A, Brenner W, Biesterfeld S, Hampel C, Thuroff JW: Impact of several histopathological prognosticators and local tumour extension on oncological outcome in pT3b/c NOMO renal cell carcinoma. BJU international 2009, 104(4):461-469.

16.Minervini A, Rosaria Raspollini M, Tuccio A, Di Cristofano C, Siena G, Salvi M, Vittori G, Sebastianelli A, Lapini A, Serni S et al: Pathological characteristics and prognostic effect of peritumoral capsule penetration in renal cell carcinoma after tumor enucleation. Urologic oncology 2014, 32(1):50.e15-22.

17.Snarskis C, Calaway AC, Wang L, Gondim D, Hughes I, Idrees MT, Kliethermes S, Maniar V, Picken MM, Boris RS et al: Standardized Reporting of Microscopic Renal Tumor Margins: Introduction of the Renal Tumor Capsule Invasion Scoring System. The Journal of urology 2017, 197(1):23-30.

18.Gu L, Li H, Wang Z, Wang B, Huang Q, Lyu X, Shen D, Gao Y, Fan Y, Li X et al: A systematic review and meta-analysis of clinicopathologic factors linked to oncologic outcomes for renal cell carcinoma with tumor thrombus treated by radical nephrectomy with thrombectomy. Cancer Treat Rev 2018, 69:112-120. 
19.Patard J-J, Leray E, Rioux-Leclercq N, Cindolo L, Ficarra V, Zisman A, Taille ADL, Tostain J, Artibani W, Abbou CC et al: Prognostic Value of Histologic Subtypes in Renal Cell Carcinoma: A Multicenter Experience. Journal of Clinical Oncology 2005, 23(12):2763-2771.

20.Cao C, Bi X, Liang J, Li L, Zhang H, Xiao Z, Xiao Z, Tian J, Wang D, Guan K et al: Long-term survival and prognostic factors for locally advanced renal cell carcinoma with renal vein tumor thrombus. BMC cancer 2019, 19(1):144.

21.Schiavina R, Borghesi M, Chessa F, Dababneh H, Bianchi L, Della Mora L, Del Prete C, Longhi B, Rizzi S, Fiorentino M et al: The Prognostic Impact of Tumor Size on Cancer-Specific and Overall Survival Among Patients With Pathologic T3a Renal Cell Carcinoma. Clinical genitourinary cancer2015, 13(4):e235-e241.

22.Du WX, Duan SF, Chen JJ, Huang JF, Yin LM, Tong PJ: Serum bone-specific alkaline phosphatase as a biomarker for osseous metastases in patients with malignant carcinomas: a systematic review and metaanalysis. Journal of cancer research and therapeutics 2014, 10 Suppl:C140-143.

23.Kattan MW, Sternberg CN, Mehmud F, Bhatt K, McCann L, Motzer RJ: Development and Validation of a Prognostic Nomogram for Progression-Free Survival in Patients with Advanced Renal Cell Carcinoma Treated with Pazopanib. Oncology 2015, 89(4):235-241.

24.Amato RJ, Flaherty A, Zhang Y, Ouyang F, Mohlere V: Clinical prognostic factors associated with outcome in patients with renal cell cancer with prior tyrosine kinase inhibitors or immunotherapy treated with everolimus. Urologic oncology 2014, 32(3):345-354.

25.Margulis V, McDonald M, Tamboli P, Swanson DA, Wood CG: Predictors of oncological outcome after resection of locally recurrent renal cell carcinoma. The Journal of urology 2009, 181(5):2044-2051.

26.Jung K, Lein M, Ringsdorf M, Roigas J, Schnorr D, Loening SA, Staack A: Diagnostic and prognostic validity of serum bone turnover markers in metastatic renal cell carcinoma. The Journal of urology 2006, 176(4 Pt 1):1326-1331.

27.Chuang Y-C, Lin ATL, Chen K-K, Chang Y-H, Chen M-T, Chang LS: PARANEOPLASTIC ELEVATION OF SERUM ALKALINE PHOSPHATASE IN RENAL CELL CARCINOMA: INCIDENCE AND IMPLICATION ON PROGNOSIS. Journal of Urology 1997, 158(5):1684-1687.

28.Blay J-Y, Rossi J-F, Wijdenes J, Menetrier-Caux C, Schemann S, Négrier S, Philip T, Favrot M: Role of interleukin- 6 in the paraneoplastic inflammatory syndrome associated with renal-cell carcinoma. International Journal of Cancer 1997, 72(3):424-430.

29.Petros FG, Metcalfe MJ, Yu KJ, Keskin SK, Fellman BM, Chang CM, Gu C, Tamboli P, Matin SF, Karam JA et al: Oncologic outcomes of patients with positive surgical margin after partial nephrectomy: a 25year single institution experience. World journal of urology 2018, 36(7):1093-1101. 
30.Marchinena PG, Tirapegui S, Gonzalez IT, Jurado A, Gueglio G: Positive surgical margins are predictors of local recurrence in conservative kidney surgery for pT1 tumors. International braz j urol: official journal of the Brazilian Society of Urology 2018, 44(3):475-482.

31.Abu-Ghanem Y, Ramon J, Berger R, Kaver I, Fridman E, Leibowitz-Amit R, Dotan ZA: Positive surgical margin following radical nephrectomy is an independent predictor of local recurrence and diseasespecific survival. World journal of surgical oncology 2017, 15(1):193.

32.Rassweiler JJ, Gozen AS: Small renal masses: a positive surgical margin does not affect survival. Nature reviews Urology 2013, 10(5):256-257.

33.Borghesi M, Brunocilla E, Schiavina R, Martorana G: Positive surgical margins after nephron-sparing surgery for renal cell carcinoma: incidence, clinical impact, and management. Clinical genitourinary cancer 2013, 11(1):5-9.

34.Ani I, Finelli A, Alibhai SM, Timilshina N, Fleshner N, Abouassaly R: Prevalence and impact on survival of positive surgical margins in partial nephrectomy for renal cell carcinoma: a population-based study. BJU international 2013, 111(8):E300-305.

35.Zisman A, Pantuck AJ, Wieder J, Chao DH, Dorey F, Said JW, deKernion JB, Figlin RA, Belldegrun AS: Risk group assessment and clinical outcome algorithm to predict the natural history of patients with surgically resected renal cell carcinoma. Journal of clinical oncology: official journal of the American Society of Clinical Oncology 2002, 20(23):4559-4566.

36.Frank I, Blute ML, Cheville JC, Lohse CM, Weaver AL, Zincke H: An outcome prediction model for patients with clear cell renal cell carcinoma treated with radical nephrectomy based on tumor stage, size, grade and necrosis: the SSIGN score. The Journal of urology 2002, 168(6):2395-2400.

37.Motzer RJ, Haas NB, Donskov F, Gross-Goupil M, Varlamov S, Kopyltsov E, Lee JL, Melichar B, Rini BI, Choueiri TK et al: Randomized Phase III Trial of Adjuvant Pazopanib Versus Placebo After Nephrectomy in Patients With Localized or Locally Advanced Renal Cell Carcinoma. Journal of clinical oncology: official journal of the American Society of Clinical Oncology 2017, 35(35):3916-3923.

38.Ravaud A, Motzer RJ, Pandha HS, George DJ, Pantuck AJ, Patel A, Chang Y-H, Escudier B, Donskov F, Magheli A et al: Adjuvant Sunitinib in High-Risk Renal-Cell Carcinoma after Nephrectomy. New England Journal of Medicine 2016, 375(23):2246-2254.

\section{Tables}




\begin{tabular}{|c|c|c|}
\hline Variables & $\mathrm{N}$ & $(\%)$ \\
\hline \multicolumn{3}{|l|}{ Sex } \\
\hline Female & 49 & $(30.8)$ \\
\hline Male & 110 & $(69.2)$ \\
\hline \multicolumn{3}{|l|}{ Age } \\
\hline$\leq 65$ years & 92 & $(57.9)$ \\
\hline$>65$ years & 67 & $(42.1)$ \\
\hline \multicolumn{3}{|l|}{ Tumor location } \\
\hline Right & 72 & $(45.3)$ \\
\hline Left & 86 & $(54.1)$ \\
\hline Bilateral & 1 & $(0.6)$ \\
\hline \multicolumn{3}{|c|}{ Open or laparoscopic surgery } \\
\hline Open surgery & 111 & $(69.8)$ \\
\hline Laparoscopic surgery & 48 & $(30.2)$ \\
\hline \multicolumn{3}{|c|}{ Radical or partial nephrectomy } \\
\hline Radical surgery & 117 & (73.6) \\
\hline Partial surgery & 42 & $(26.4)$ \\
\hline \multicolumn{3}{|c|}{ Pathology T stage (AJCC 7th edition) } \\
\hline T3a & 134 & $(84.3)$ \\
\hline T3b & 14 & $(8.8)$ \\
\hline T3c & 7 & (4.4) \\
\hline T4 & 4 & $(2.5)$ \\
\hline \multicolumn{3}{|l|}{ Renal cell carcinoma type } \\
\hline Clear cell & 129 & $(81.1)$ \\
\hline Chromophobe & 14 & $(8.8)$ \\
\hline Papillary & 13 & $(8.2)$ \\
\hline Collecting duct & 1 & $(0.6)$ \\
\hline Xp11.2 translocation & 2 & $(1.3)$ \\
\hline \multicolumn{3}{|l|}{ Fuhrman grade } \\
\hline 1 & 1 & $(0.6)$ \\
\hline 2 & 69 & $(43.7)$ \\
\hline 3 & 65 & $(41.1)$ \\
\hline 4 & 2 & $(14.6)$ \\
\hline \multicolumn{3}{|l|}{ Necrosis } \\
\hline Absent & 46 & $(30.5)$ \\
\hline Focal & 77 & $(51.0)$ \\
\hline Extensive & 28 & (18.5) \\
\hline \multicolumn{3}{|l|}{ Capsule penetration } \\
\hline No & 109 & $(69.9)$ \\
\hline Yes & 47 & $(30.1)$ \\
\hline \multicolumn{3}{|l|}{ Hilar vein involvement } \\
\hline No & 57 & $(36.3)$ \\
\hline
\end{tabular}




\begin{tabular}{|l|c|c|} 
Yes & 100 & $(63.7)$ \\
\hline Surgical margin & & $(93.3)$ \\
\hline No & 97 & $(6.7)$ \\
\hline Yes & 7 & \\
\hline Sinus fat invasion & 57 & $(37.8)$ \\
\hline No & 94 & $(62.3)$ \\
\hline Yes & & \\
\hline Muscular branch involvement & 68 & $(44.2)$ \\
\hline No & 86 & $(55.8)$ \\
\hline Yes & & \\
\hline Sarcomatoid differentiation & 149 & $(93.7)$ \\
\hline No & 10 & $(6.3)$ \\
\hline Yes & & \\
\hline Lymphadenopathy & 144 & $(92.3)$ \\
\hline No & 12 & $(7.7)$ \\
\hline Yes & & \\
\hline BMI $>$ 25 & 64 & $(52.5)$ \\
\hline No & 58 & $(47.5)$ \\
\hline Yes & & \\
\hline Postoperative complication & 135 & $(84.9)$ \\
\hline No & 24 & $(15.1)$ \\
\hline Yes & & \\
\hline Adjuvant targeted therapy & 136 & $(86.1)$ \\
\hline No & 22 & $(13.9)$ \\
\hline Yes & & \\
\hline Disease recurrence & & $(74.8)$ \\
\hline No & $33.0 \pm 26.8$ \\
\hline Yes & & $(25.2)$ \\
\hline Disease-free survival (months) & & \\
\hline
\end{tabular}

AJCC, American Joint Committee on Cancer; BMI, body mass index 
Table 2. Univariate analysis of possible predictor of disease recurrence in patients with locally advanced renal cell carcinoma

\begin{tabular}{|l|c|c|c|}
\hline Variables & \multicolumn{2}{|c|}{ Disease recurrence } & \multirow{2}{*}{-value } \\
\cline { 2 - 3 } & $\begin{array}{c}\text { No } \\
(\mathrm{N}=119)\end{array}$ & $\begin{array}{c}\text { Yes } \\
\text { N = 40) }\end{array}$ & \\
\hline Male sex & $80(67.23)$ & $30(75.00)$ & 0.357 \\
\hline Age $>65$ years & $50(42.02)$ & $17(42.50)$ & 0.957 \\
\hline BMI $>25 \mathrm{~kg} / \mathrm{m}^{2}$ & $47(51.65)$ & $11(35.48)$ & 0.120 \\
\hline Partial nephrectomy approach & $36(30.25)$ & $6(15.00)$ & 0.058 \\
\hline Pathology T stage (AJCC 7th edition) > T3a & $11(9.24)$ & $14(35.00)$ & $<0.001$ \\
\hline Fuhrman grade 3 or 4 & $56(47.46)$ & $32(80)$ & 0.003 \\
\hline Clear cell type & $99(83.19)$ & $30(75.00)$ & 0.252 \\
\hline Presence of extensive necrosis & $17(15.18)$ & $11(28.21)$ & 0.071 \\
\hline Presence of capsule penetration & $28(23.93)$ & $19(48.72)$ & 0.004 \\
\hline Positive surgical margin & $5(5.95)$ & $2(10.00)$ & 0.516 \\
\hline Sarcomatoid differentiation & $5(4.20)$ & $5(12.50)$ & 0.123 \\
\hline Presence of lymphadenopathy & $6(5.08)$ & $6(15.79)$ & 0.072 \\
\hline Type O blood & $51(42.86)$ & $15(37.50)$ & 0.552 \\
\hline Perioperative blood transfusion & $6(26.09)$ & $8(47.06)$ & 0.169 \\
\hline Preoperative leukocytosis & $2(1.75)$ & $3(7.50)$ & 0.111 \\
\hline Preoperative thrombocytosis & $10(8.40)$ & $10(25.00)$ & 0.006 \\
\hline Preoperative anemia & $62(52.10)$ & $27(67.50)$ & 0.090 \\
\hline Preoperative hematuria & $40(33.61)$ & $10(25.64)$ & 0.353 \\
\hline Hypercalcemia & $1(0.87)$ & $0(0.00)$ & 1.000 \\
\hline Elevated serum creatinine & $13(10.92)$ & $3(7.50)$ & 0.763 \\
\hline Elevated serum alkaline phosphatase (alk-p) & $13(11.30)$ & $9(25.71)$ & 0.035 \\
\hline Elevated serum lactate dehydrogenase (LDH) & $17(14.66)$ & $9(25.00)$ & 0.150 \\
\hline Elevated serum alanine transaminase (ALT) & $12(10.08)$ & $6(15.00)$ & 0.397 \\
\hline Elevated serum aspartate transaminase (AST) & $4(3.42)$ & $2(5.26)$ & 0.635 \\
\hline Elevated serum -glutamyl transpeptidase (rGT) & $8(7.34)$ & $7(20.59)$ & 0.049 \\
\hline Perioperative complications & $20(16.81)$ & $4(10.00)$ & 0.298 \\
\hline Adjuvant targeted therapy & $13(11.02)$ & $9(22.50)$ & 0.070 \\
\hline
\end{tabular}

Data are presented as number (percentage).

Red font indicates statistical significance $(\mathrm{p}<0.05)$.

BMI, body mass index; AJCC, American Joint Committee on Cancer 


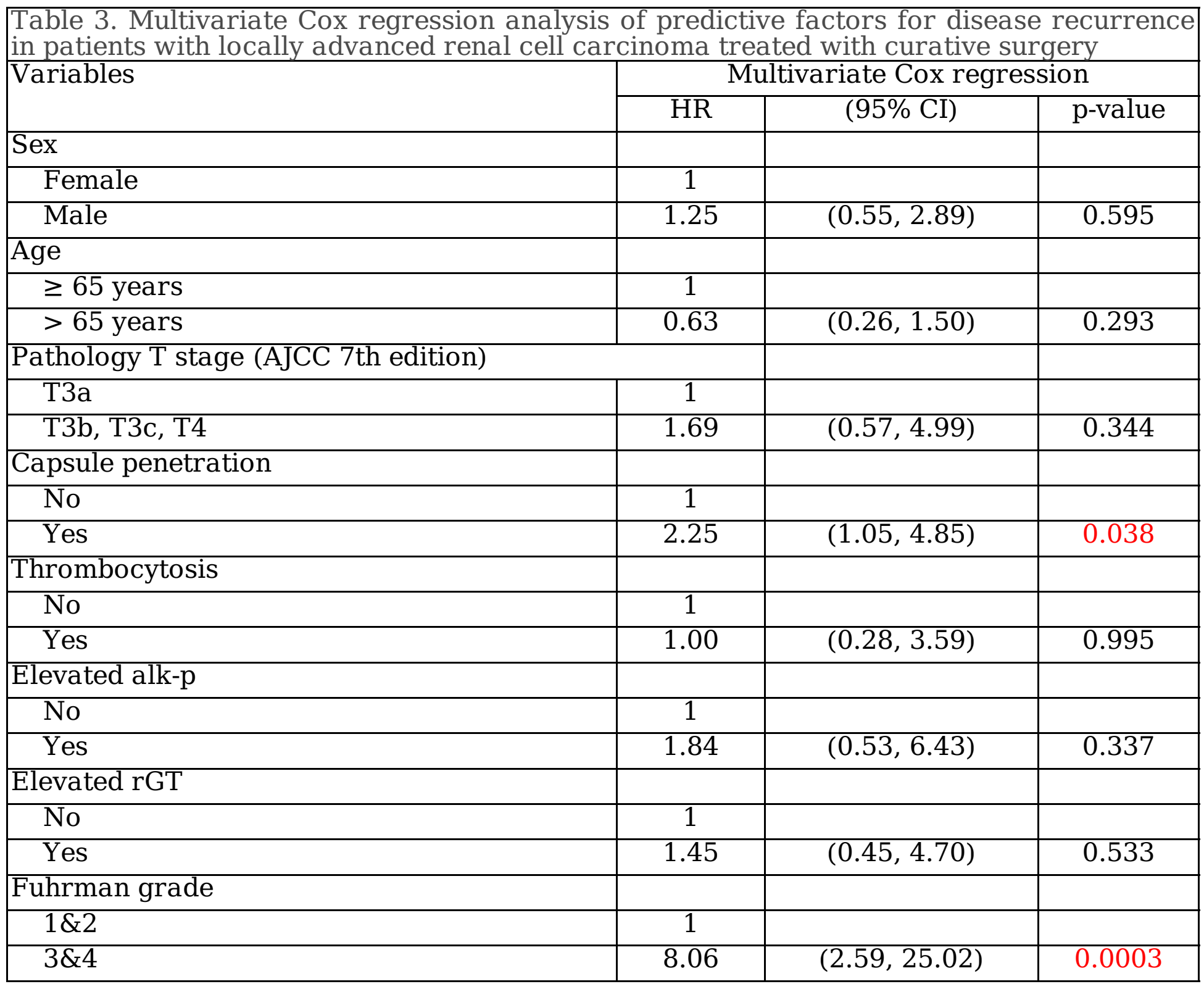

Red font indicates statistical significance $(\mathrm{p}<0.05)$.

HR, hazard ratio; CI, confidence interval; AJCC, American Joint Committee on Cancer; rGT, serum $\gamma$-glutamyl transpeptidase; alk-p, serum alkaline phosphatase

\section{Figures}




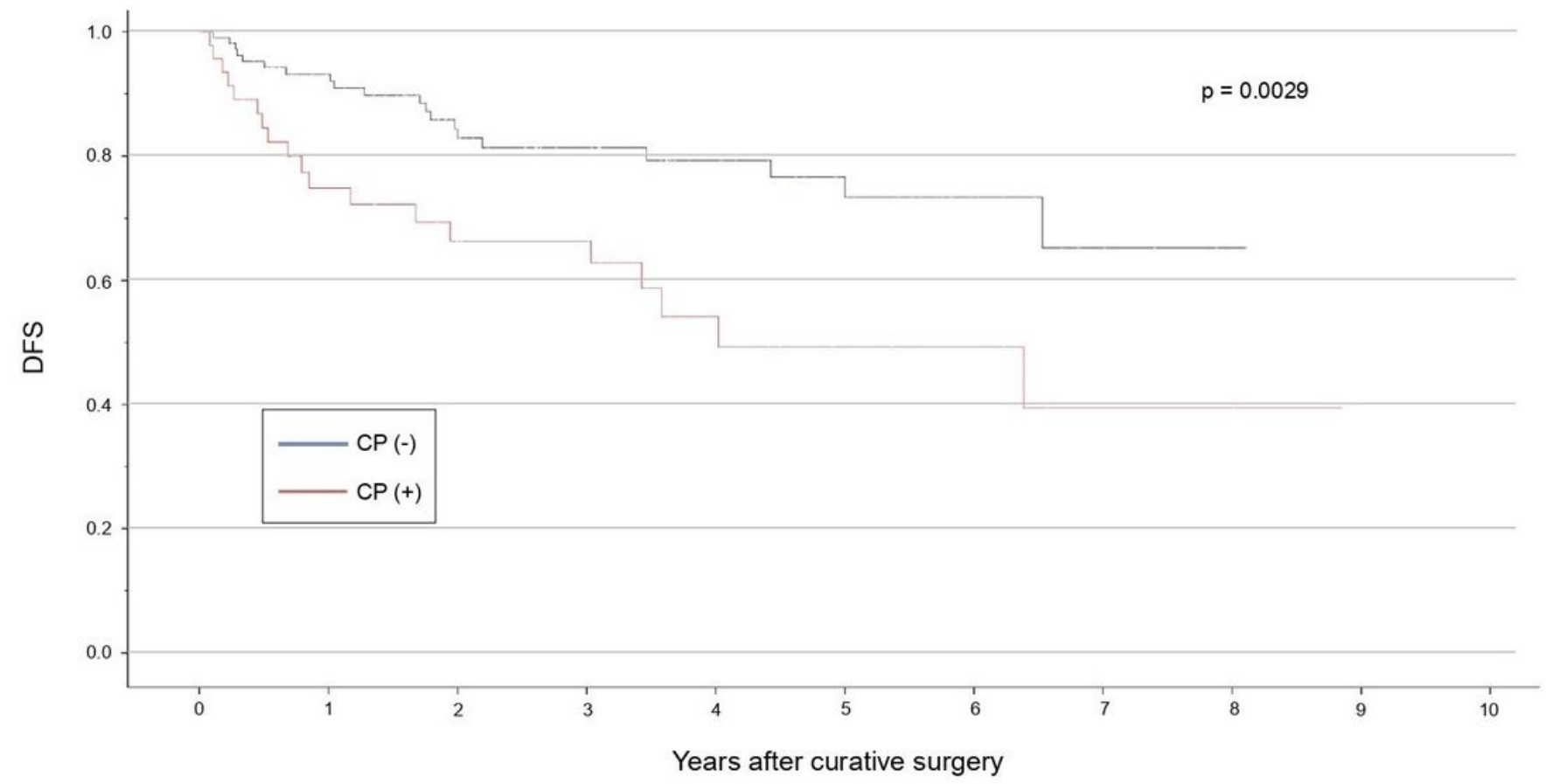

Number at risk:

$\begin{array}{rrrrrrrrrrr}\mathrm{CP}(-) & 109 & 83 & 57 & 45 & 33 & 24 & 12 & 5 & 2 & 0 \\ \mathrm{CP}(+) & 47 & 29 & 21 & 20 & 11 & 7 & 6 & 2 & 2 & 0\end{array}$

* CP : Capsule penetration

\section{Figure 1}

Kaplan-Meier curves for disease-free survival (DFS) according to capsule penetration (CP) 


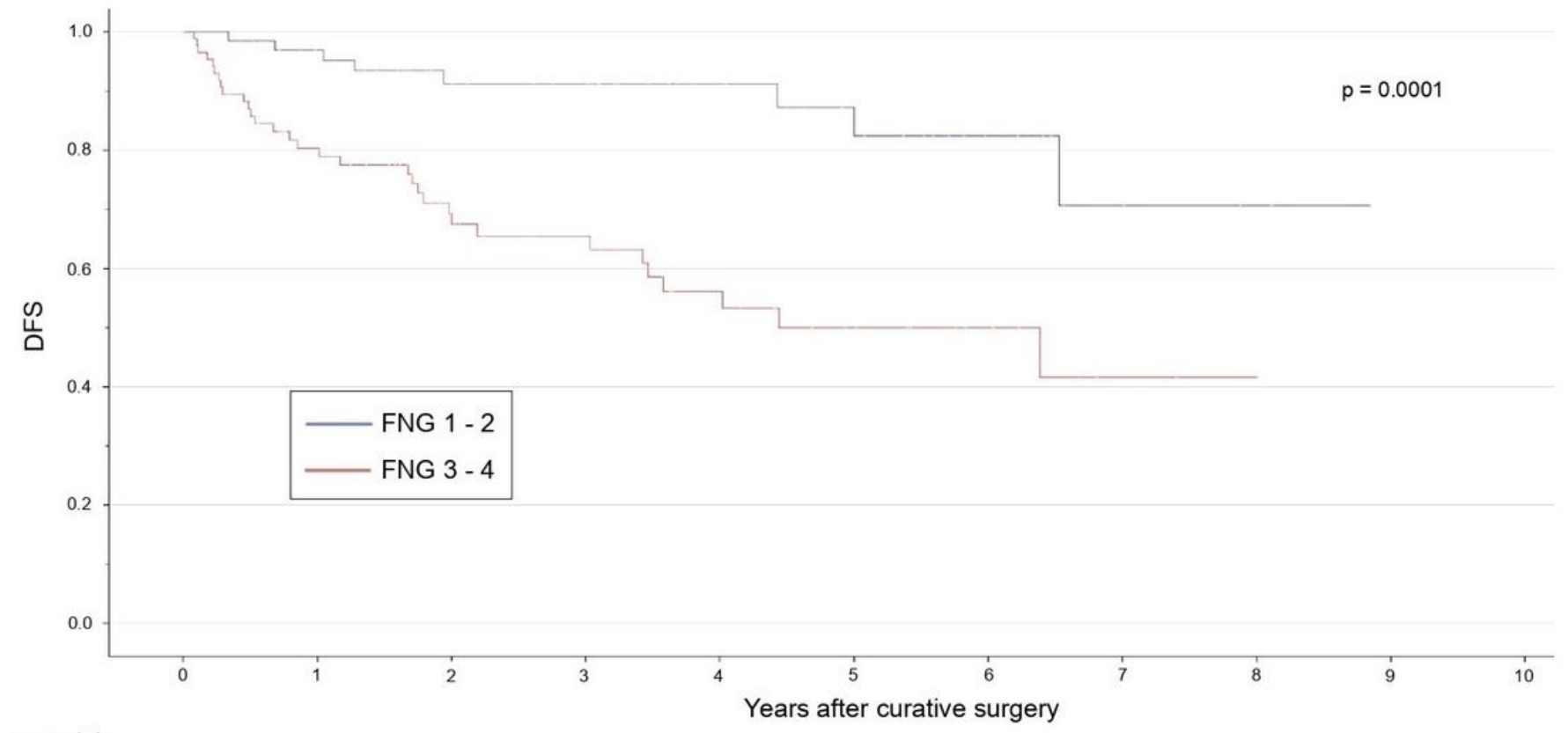

Number at risk:

$\begin{array}{lllllllllll}\text { FNG 1 - } 2 & 70 & 56 & 41 & 37 & 25 & 18 & 10 & 5 & 3 & 0 \\ \text { FNG 3 - } 4 & 88 & 57 & 38 & 29 & 20 & 13 & 8 & 2 & 1 & 0\end{array}$

* FNG : Fuhman grade

\section{Figure 2}

The Kaplan-Meier curves for disease-free survival (DFS) according to Fuhrman grade (FNG) 